\title{
Constitutive parameters for earthquake rupture dynamics based on high-velocity friction tests with variable sliprate
}

\author{
Eiichi Fukuyama · Kazuo Mizoguchi
}

Received: 3 March 2009 / Accepted: 7 October 2009 / Published online: 3 November 2009

(C) The Author(s) 2009. This article is published with open access at Springerlink.com

\begin{abstract}
To reproduce the dynamic rupture process of earthquakes, the fault geometry, initial stress distribution and a frictional constitutive law on the fault are important parameters as initial and boundary conditions of the system. Here, we focus on the frictional constitutive relation on the fault. During a high-speed rupture, fault strength decreases as slip develops which can be described by a slip weakening equation. To understand the physical process of stress breakdown during the dynamic rupture of earthquakes, we investigated the friction behavior of rocks in the laboratory by direct measurements of traction evolution with slip in response to a given slip history. We employed a highspeed rotary shear apparatus introduced at National Research Institute for Earth Science and Disaster Prevention (NIED). This apparatus has a capability of sliding with predefined variable velocities using a servo-controlled system. We used a pair of granite cylindrical specimens with a diameter of $25 \mathrm{~mm}$. As an input signal, we used a regularized Yoffe function to investigate the scale dependence of fracture energy and slip weakening distance $\left(D_{\mathrm{c}}\right)$. We observed a positive correlation between $D_{\mathrm{c}}$ and total slip, keeping the maximum slip velocity constant. These conditions correspond to those for earthquakes with the same stress drop and varying magnitudes. Finally, we used a
\end{abstract}

E. Fukuyama $(\varangle) \cdot$ K. Mizoguchi

National Research Institute for Earth Science

and Disaster Prevention, 3-1 Tennodai, Tsukuba,

Ibaraki 305-0006, Japan

e-mail: fuku@bosai.go.jp real fault motion; a fault parallel velocity seismogram observed at PS10, $3 \mathrm{~km}$ away from the surface fault trace and above the high slip region during the 2002 Denali, Alaska, earthquake. We compared the seismological fracture energy with the corresponding $D_{\mathrm{c}}$. The relation is linear with an inflection point at $D_{\mathrm{c}}=$ $0.2 \mathrm{~m}$, where the gradient changes. Another interesting feature is that the maximum value of $D_{\mathrm{c}}$ is about $4 \mathrm{~m}$ even if the total slip exceeds $12 \mathrm{~m}$.

Keywords Slip weakening distance .

Seismological fracture energy *

High-velocity rotary-shear apparatus

\section{Introduction}

During the propagation of earthquake dynamic rupture, elastic strain energy stored in the source region is dissipated in many ways such as frictional work, seismic radiation, heat generation, and creation of new fault surfaces (e.g., Kostrov and Das 1988, Chapt. 2.2). How these energies are partitioned is one of the most important topics in earthquake rupture dynamics and characterizes the earthquake rupture. As a part of this energy dissipation process, the fault strength decreases as fault slip advances when the fault ruptures at high slip rate $(\sim 1 \mathrm{~m} / \mathrm{s})$. The fracture energy, which is defined as a frictional work on the fault, characterizes this energy dissipation process during high slip rate rupture. The fracture energy is characterized by a break- 
down strength drop and a slip weakening distance. The slip weakening distance is defined as the amount of slip required to decrease the strength from static friction (peak friction) to dynamic one (steady-state).

It is evident that a single parameter cannot define the friction behavior during high slip velocity sliding. Instead, we should say that "slip-history" (or slip velocity-history) controls the behavior of friction. From the physical point of view, slip-history dependence and slip velocity-history dependence are equivalent because either slip or slip-velocity can be an independent variable that describes the physical process. Because we treat a transient process of slip in this paper, we investigate the friction behavior based on the slip-history dependence.

From the geological observation of exhumed ancient faults, the actual slip zone width during the earthquake is found to be very narrow, maybe on the order of millimeters or less, and surrounded by a damage zone (e.g., Chester and Chester 1998). As theoretically predicted by Yamashita (2000) and observed in the field by Di Toro et al. (2005), tensional cracks develop along the tensional side of the fault during high slip rupture, which causes the damage zone. This formation process of the damage zone helps broaden the fault zones. Therefore, the structure of a fault zone seems closely related to the slip weakening behavior during the dynamic rupture of earthquakes. However, how the fault zone thickness affects the dynamic rupture still remains an open question. There is a friction experiment at high slip rate with a gouge layer (Mizoguchi et al. 2009). In their experiment, a 1-mm thick gouge was used, which suppressed the temperature raise during the experiments compared to the case of rock-rock friction experiment by Mizoguchi et al. (2007). This indicates that the thickness of pre-existing gouge layer might be related to the heat production rate during the high slip sliding.

Therefore, in the fault zone, most of coseismic slips are considered to occur in a very thin slip zone. If an essential feature of the slip weakening behavior at high slip velocity rupture lies in a millimeter thickness slip zone, it is quite reasonable to investigate the faulting motion using the high velocity rotary shear apparatus in the laboratory that we recently introduced and developed (see also Mizoguchi and Fukuyama 2009). With the apparatus, it is feasible to create a slip zone with 0.1 - $\mathrm{mm}$ thickness after several meters of slip in the laboratory to reproduce the faulting motions and to investi- gate the physical mechanism of slip weakening in more detail.

In this paper, we briefly review slip weakening distance to clarify the target of the experiments. Then, we show the results of a series of laboratory experiments using a high-velocity servo-controlled rotaryshear apparatus to reproduce realistic conditions for earthquake rupture. As an input to the apparatus, we use a regularized Yoffe function (Tinti et al. 2005a) as a proxy of the slip velocity function during a dynamic rupture to capture a fundamental feature of earthquake slip. Then, to realize a more realistic situation, we use the slip history from the PS10 seismogram as an input. The PS10 seismogram was obtained close to the Denali fault during the 2002 Denali earthquake $\left(M_{\mathrm{w}} 7.9\right)$ (Ellsworth et al. 2004) and its fault-parallel component is considered a good approximation of faulting motion of the Denali fault. Using the obtained traction evolutions as a function of slip, we discuss the slip weakening distance and seismological fracture energy. As we will describe in detail later, our present experiments are currently limited to non-melting conditions because we want to avoid complications due to phase transitions in the rocks.

\section{Slip-weakening distance}

During the earthquake rupture, shear strength on the fault decreases as slip develops as schematically shown in Fig. 1. We can define a critical slip distance (slip weakening distance, $D_{\mathrm{c}}$ ) at which fault weakening stops and the shear traction reaches more or less steady-state level. This is a transitional process from static to dynamic friction. Such weakening has been predicted theoretically (e.g., Ida 1972; Palmer and Rice 1973) and confirmed in the laboratory (e.g., Dieterich 1978; Ohnaka et al. 1987; Tsutsumi and Shimamoto 1997).

In seismological observations, slip weakening distances were measured from a spatiotemporal slip function on the fault during large earthquakes (e.g., Ide and Takeo 1997; Tinti et al. 2005b). The slip function is usually estimated by a waveform inversion of strong ground motions and/or teleseismic seismograms (e.g., Hartzell and Heaton 1983; Fukuyama and Mikumo 1993; Wald and Heaton 1994; Yoshida et al. 1996; Dreger and Kaverina 2000; Ji et al. 2002; Sekiguchi and Iwata 2002). However, it is quite difficult to estimate accurately the spatiotemporal history of slip on the fault because the 


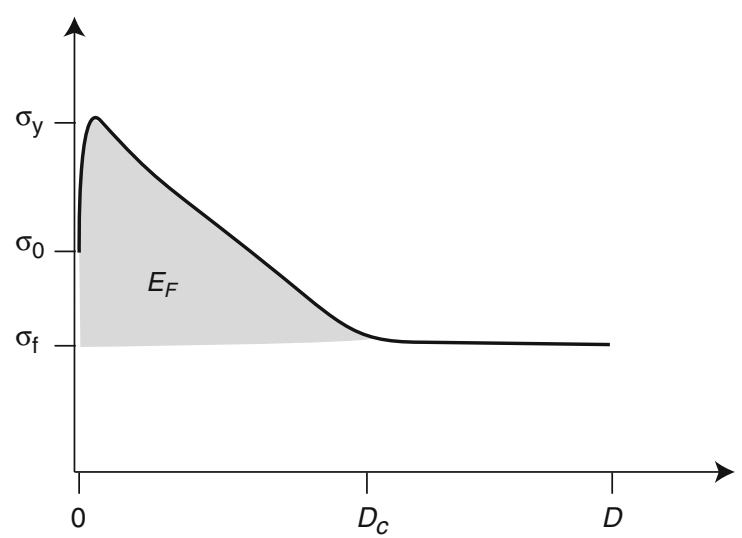

Fig. 1 Schematic illustration of slip-weakening behavior. $D_{\mathrm{c}}$ is slip-weakening distance, $D$ is final slip. $\sigma_{\mathrm{y}}, \sigma_{0}$ and $\sigma_{\mathrm{f}}$ are yield stress, initial stress and frictional stress, respectively. $E_{F}$ is seismological fracture energy

waveform inversion requires various assumptions during the analysis which includes fault geometry, shape of slip velocity function, velocity structure between earthquake source and observation sites, and smoothness constraint of the parameters to be estimated. Thus the results depend on these assumptions (Beresnev 2003). And it is pointed out that a tiny change in slip velocity function results in very different slip weakening behaviors (Piatanesi et al. 2004; Tinti et al. 2009).

Mikumo et al. (2003) and Fukuyama et al. (2003) proposed a technique for the estimation of slip weakening distance from the slip time function on the fault. Fukuyama and Mikumo (2007) extended this idea for the application of near-fault seismograms. Since the fault parallel components of near-fault seismograms for vertical strike slip fault earthquakes can be considered as a proxy of the fault motion at the middle of the fault embedded in infinite medium considering the free surface as a mirror image interface, we can roughly determine the slip weakening distance from such near-fault waveforms. From their analyses, the slip weakening distance was of the order of $1 \mathrm{~m}$ for magnitude 7 earthquakes.

Since the slip weakening distance is a difficult parameter to estimate accurately by seismological observations as describe above, fracture energy has been proposed as an alternative parameter to characterize the earthquake dynamic rupture. The seismological fracture energy $E_{\mathrm{F}}$ is defined as

$E_{\mathrm{F}}=\int_{0}^{D_{\mathrm{c}}} S(\Delta u)-S\left(D_{\mathrm{c}}\right) \mathrm{d} \Delta u$ where $S($.$) is a slip weakening curve function (sche-$ matically illustrated in Fig. 1). Guatteri and Spudich (2000) demonstrated that for band-limited analyses of seismic waveforms, slip weakening distance may not be determined uniquely and high frequency waves are required, which are usually difficult to be extracted from observed seismograms because of the heterogeneity of the crust. Instead, it is pointed out that seismological fracture energy can be estimated stably (Ide 2002; Tinti et al. 2005b) because the seismological fracture energy is an integration quantity. Tinti et al. (2005b) and Mikumo and Fukuyama (2006) estimated the fracture energy as $\sim 5 \mathrm{MJ} / \mathrm{m}^{2}$ for magnitude 7 earthquakes and they found a scale-dependence of seismological fracture energy on earthquake magnitudes. Then a question arises what determines the fracture energy of earthquakes. To investigate this question, we conducted laboratory experiments to measure the slip weakening distance and fracture energy directly.

Several mechanisms have been proposed to explain slip weakening which include frictional wear, lubrication, melting and thermal pressurization. Frictional wearing is one of possible mechanisms where worn (gouge) material on the fault weakens the fault. Matsu'ura et al. (1992) theoretically explained the slip weakening data obtained by Ohnaka et al. (1987) based on abrasion of the fault. Chambon et al. (2002) conducted friction experiments at slow slip rate for gougefilled fault and observed that the gouge layer caused a slip weakening behavior. Mizoguchi et al. (2009) confirmed that even at high slip rate, gouge-sandwiched fault weakens as slip advances. Melosh (1996) proposed acoustic fluidization as a weakening mechanism where the vibration of gouge particles during high speed slip reduces the effective normal stress. Silica gel lubrication is proposed by Goldsby and Tullis (2002) and Di Toro et al. (2004); it weakens the contacts between gouge particles. Hirose and Shimamoto (2003, 2005) and Spray (2005) observed slip weakening during high slip rate sliding when melting occurred. Thermal pressurization was proposed by Sibson (1973) and modeled by Lachenbruch (1980), Mase and Smith (1987), Andrews (2002), Wibberley and Shimamoto (2005), Bizzarri and Cocco (2006) and Rice (2006) and many others. It is difficult to confirm in the laboratory whether thermal pressurization occurs or not because no footprints of thermal pressurization remain after high-speed slip; all the above studies are based on theoretical considerations. 
Table 1 Specification of high velocity rotary shear apparatus

\begin{tabular}{ll}
\hline Elements & Specifications \\
\hline Electric motor power & $5 \mathrm{~kW}$ \\
Maximum rotation speed & $50 \mathrm{rps}$ (rotation per second) \\
Maximum rotation acceleration & 2,034 rpss (rotation per \\
& second square) \\
Air actuator capacity & 2 or $20 \mathrm{kN}$ maximum \\
Tachometer resolution & 2,000 pulse/rotation \\
Torque gauge measurement range & 28 or 300 Nm maximum \\
\hline
\end{tabular}

Although there are various weakening mechanisms and some of them might occur simultaneously, seismological observations will not be able to distinguish them. Thus, we expect that by comparing the results of laboratory experiments with those from seismological observations especially on their scaling features, we will be able to investigate the breakdown process during large earthquakes.

\section{High-velocity rotary shear apparatus}

To measure the traction behavior as a function of slip during earthquake rupture, from which we can estimate the slip weakening distance and seismological fracture energy, we employed a high-speed rotary-shear apparatus installed at NIED. The apparatus is designed for variable slip rate experiments and is based on the rotary-shear apparatus developed by Shimamoto and Tsutsumi (1994) and Shimamoto et al. (2003). It consists of a servo-controlled electric motor, an air actuator, a tachometer, a torque gauge, and an axial displacement-meter as schematically illustrated in Fig. 2. The detailed specifications of this apparatus are shown in Table 1. In this apparatus, torque gauge and air actuator are designed to be interchangeable between two different measurement ranges. A 1/100 decelerationgear can be attached as an option to achieve a very slow rotation speed but we did not use this gear in the present experiments.

Since the slip rate varies with the radial position of the cylindrical specimen, we used the "equivalent slip velocity," $v_{\text {eq }}$ (in $\mathrm{m} / \mathrm{s}$ ), which is defined as

$v_{\text {eq }}=\frac{4 \pi}{3} r R$

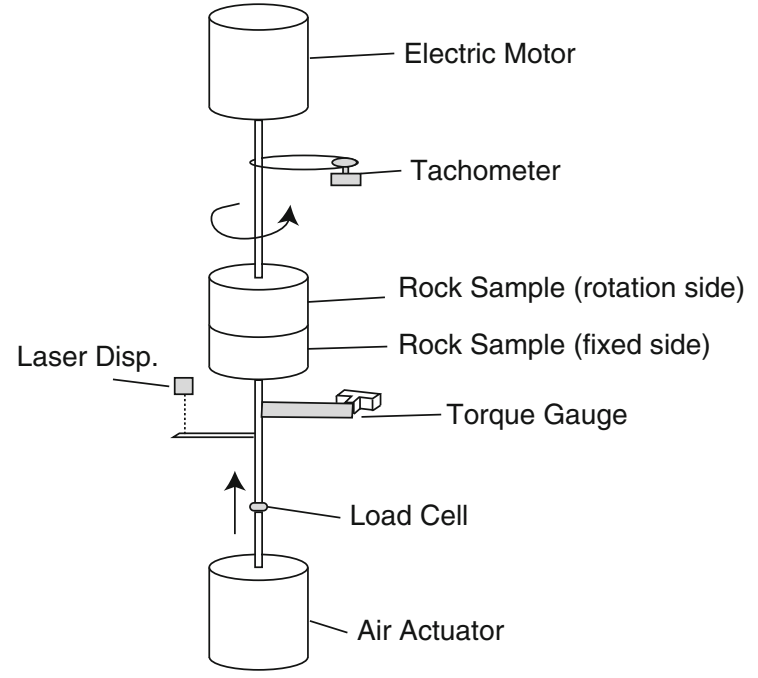

Fig. 2 Schematic illustration of high-speed rotary-shear apparatus installed at National Research Institute for Earth Science and Disaster Prevention

where $R$ is rotation speed (in rps, rotation per second), $r$ is the radius of the cylindrical specimens (in meter). In this definition, $v_{\text {eq }}$ multiplied by shear traction and the area of the fault surface gives the total frictional work rate if shear traction is constant over the slipping plane. It should be noted that Eq. 2 is identical to the definitions made by Hirose and Shimamoto (2005) and Mizoguchi et al. (2007). Since we used solid cylindrical specimens without hollows, we set the inner radius of the specimen to zero in their formulation. We use this "equivalent slip velocity" as slip velocity throughout this paper.

Since the electric motor is controlled by a servo feedback system, any shape of slip rate function can be applied in addition to a very broad range of rotation speed up to the maximum rotation speed of $50 \mathrm{rps}$ and the maximum rotation acceleration of 2,034 rpss (rotation per second square), which corresponds to $2.62 \mathrm{~m} / \mathrm{s}$ and $107 \mathrm{~m} / \mathrm{s}^{2}$, respectively, for a $25 \mathrm{~mm}$ diameter sample. The air actuator keeps a constant normal stress by compensating vertical displacements perpendicular to the slip surface due to an air cushioning effect of the air actuator.

We used a pair of cylindrical samples of granite sampled from a quarry in Aji, Kagawa Prefecture, southwest Japan (called Aji granite) for the Yoffe experiments shown in Sect. 4 and those from a quarry in Inada, Ibaraki Prefecture, central Japan (called Inada 
granite) for the Denali experiments shown in Sect. 5. Aji and Inada granites are basically the same composition, but the grain size of the Aji granite is slightly finer than that of the Inada.

One of the two specimens rotates with respect to the other contacting one of the end surfaces of each speci$\mathrm{men}$. The dimension of the sample is $25 \mathrm{~mm}$ in diameter and $40 \mathrm{~mm}$ in length. Since it is practically impossible to prepare a sample whose end surfaces are perfectly flat and co-parallel, pre-sliding is conducted to grind the contacted surfaces before all the experiments for more than 1,000 rotations at a speed of $0.83 \mathrm{rps}$ (or equivalent slip rate of $0.044 \mathrm{~m} / \mathrm{s}$ ) under the same normal stress condition. This pre-sliding procedure homogenizes the surface condition created by the previous experiment and memorized in the sample. Thus, at each experiment, the surface condition is considered to be the same in the sense that the sliding surface is ground in a same way.

However, this pre-sliding cannot prepare perfectly the same condition for a series of experiments because during the experiment, the sliding surface continues to update at every moment due to wear. If a big grain is included compared to other grains in the specimen, it will contaminate the composition of the surface. Since the rock sample is not perfectly homogeneous, we cannot avoid such situations.

Mizoguchi and Fukuyama (2009) conducted a series of experiments with various constant slip velocities under various normal stresses using Inada granite and Zimbabwe gabbro. They confirmed that the friction behavior at steady-state changes in a consistent way; as normal stress increases or slip velocity increases, the friction decreases. And there is a transition region between slow and fast slip velocity. These basic data might give us a fundamental understanding of friction behavior of the Inada granite sample. However, it should be pointed out that even in constant slip-velocity experiments, slip velocity should be accelerated from stationary state to the target velocity at the beginning of experiments. We found that a major weakening of friction occurs during this acceleration stage. Therefore, how rapidly the slip accelerates to the target velocity affects the way of weakening. So the constant slip velocity experiments done by Mizoguchi and Fukuyama (2009) did not provide us with a simple interpretation for the understanding a transient weakening process that we are discussing here.

\section{Experiments with regularized Yoffe function}

Most people might think that the simplest slip velocity history to be given in the experiments is the constant slip velocity case. However, it is not true in high slip velocity experiments. Since the weakening of friction starts to occur when the slip velocity increases from zero (or very small value) to a target velocity. And how the apparatus accelerates the slip to the target velocity affects the weakening curve of the friction. Therefore, we cannot avoid this effect when investigating the weakening curve of slip. It is natural that the initial acceleration contributes to the weakening process because the wear starts to occur immediately after the slip starts. In this stage, gouge particles are created due to the wear, which weakens the friction. Therefore, it is necessary to define the whole process of slip velocity function instead of assuming constant slip velocities.

To capture a fundamental feature of the friction behavior at transiently high slip sliding, we used a regularized Yoffe function as inputs of experiments. The regularized Yoffe function was proposed by Tinti et al. (2005a) as a kinematic slip velocity function that is consistent with dynamic fracture mechanics. Since the apparatus is controlled by slip rate functions, it is suitable to use the regularized Yoffe function for understanding the slip weakening behavior. The original Yoffe function is the analytical solution for a fixed length tensile crack propagating at a constant speed in 2D medium (Broberg 1999, Chapt. 6.2). And due to the stress concentration at the crack tip, shear stress diverges at the crack tip. Tinti et al. (2005a) found that the regularized Yoffe function, which is obtained by convolving triangle function with the original Yoffe function, has a slip weakening feature and the slip distance is related to the width of the triangle function to be convolved.

Since the apparatus can precisely control the slip rate during the experiments, we used the regularized Yoffe function as an input to the apparatus to investigate the effect of the shape of slip velocity function to the slip weakening distance. We prepared two regularized Yoffe functions (Fig. 3). One has a short slip weakening distance and the other has a long one. Short and long slip weakening distance functions are achieved by setting the peak slip velocity time ( $T_{\text {acc }}$ in Tinti et al. 2005a) as 10 and $40 \%$ of the rise time, respectively. Both functions have the same maximum slip velocity $(1.0 \mathrm{~m} / \mathrm{s})$ and final displacements. We also prepared 


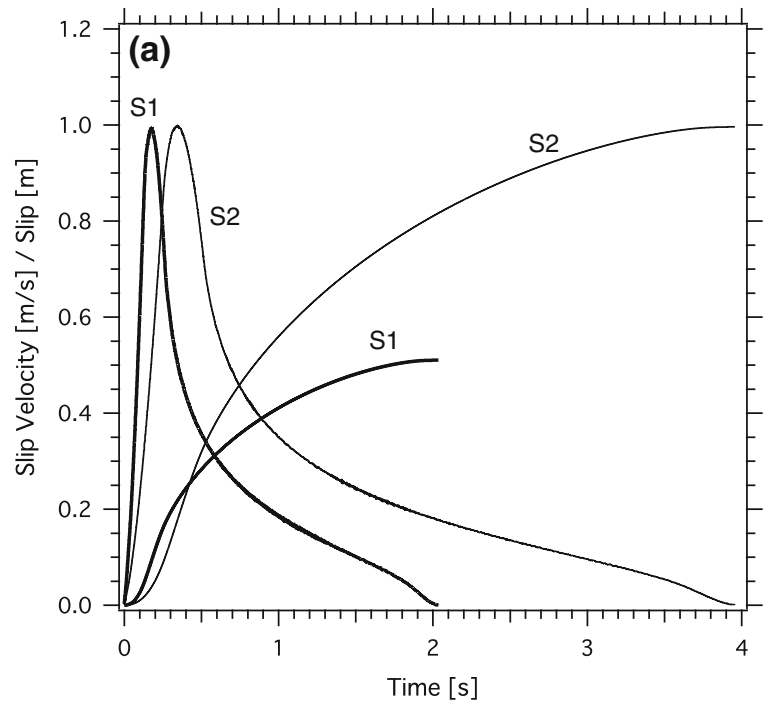

Fig. 3 Regularized Yoffe functions used for the experiments. a Sharp onset functions (peak velocity time is set to $10 \%$ of the rise time). Slip and slip velocity functions of short rise time (0.5 $\mathrm{m}$ total slip, $\mathrm{S} 1$, thick lines) and long rise time $(1.0 \mathrm{~m}$ total slip, S2, thin lines) are shown. b Gentle onset functions

two different total slips $(0.5$ and $1 \mathrm{~m})$ for each Yoffe function. Thus, in total, we prepared four different regularized Yoffe functions for the experiments (Fig. 3).

To make slip conditions simple, we conducted all experiments under non-melting conditions with a normal stress of $1 \mathrm{MPa}$. We confirmed that by applying a normal stress more than $1 \mathrm{MPa}$, visible melting started to occur. Under the melting condition, there are two different mechanisms, frictional wear and melting, occurring successively as shown in Hirose and Shimamoto (2003). This complicates the interpretation of the results with respect to one mechanism. Thus, in the present study, we conducted the experiments under non-melting conditions and the experiments with melting will be a future target. But, strictly speaking, it is quite difficult to identify if melting occurs or not during the experiments because partial melting around the gouge grains might occur without any luminous materials outside the sample. Here, "non-melting" condition means that we could not observe any visible melting during the experiments. We do not deny a possibility of small scale melting where some of the surfaces of gouge grains started to melt.

We conducted several experiments with the same experimental conditions. But we observed significant

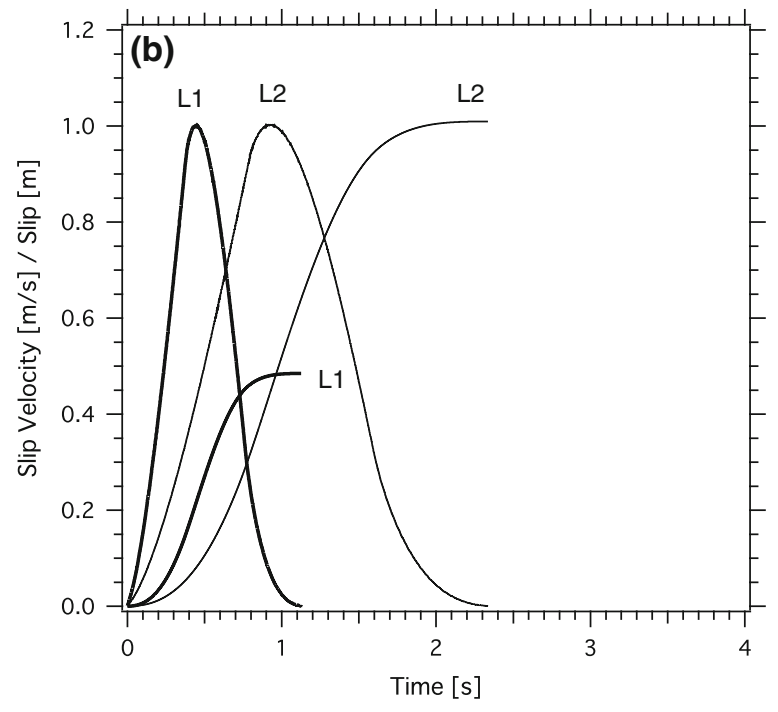

(peak velocity time is set to $40 \%$ of the rise time). Slip and slip velocity functions of short rise time $(0.5 \mathrm{~m}$ total slip, L1, thick lines) and long rise time (1.0 $\mathrm{m}$ total slip, L2, thin lines) are shown. In all functions, maximum slip velocity is set at $1.0 \mathrm{~m} / \mathrm{s}$

differences between the experiments, which might be caused a tiny difference on the sliding surface. In the present experiments, the sliding surfaces changes at every moment due to wear of the fault. Therefore, we first set the initial friction coefficient between $1.04 \pm$ 0.12 by sliding the surface at a very slow slip rate of $8.7 \times 10^{-4} \mathrm{~m} / \mathrm{s}(1 / 60 \mathrm{rps})$. When the friction coefficient fell into the predefined range $(1.04 \pm 0.12)$, we started the experiments. Even though the starting friction level is the same, the behavior sometimes changes accidentally. We think this is because the rock specimens are not completely uniform along the rotation axis; because the sliding surfaces are updated at every moment, surface condition might change due to the unexpected inclusion of the minerals or large size grain that appears on the surface during the sliding. Thus we only used data of experiments that were similar, which ensures the obtained data are reproducible.

We think the exclusion of the outliers of the data is reasonable because the outliers are caused by unexpected change in the composition of sliding surfaces, especially by the generation of large gouge particles. Mizoguchi and Fukuyama (2008) found that from the observation of thin sections of the rock samples after the high velocity experiments across the sliding surfaces, 


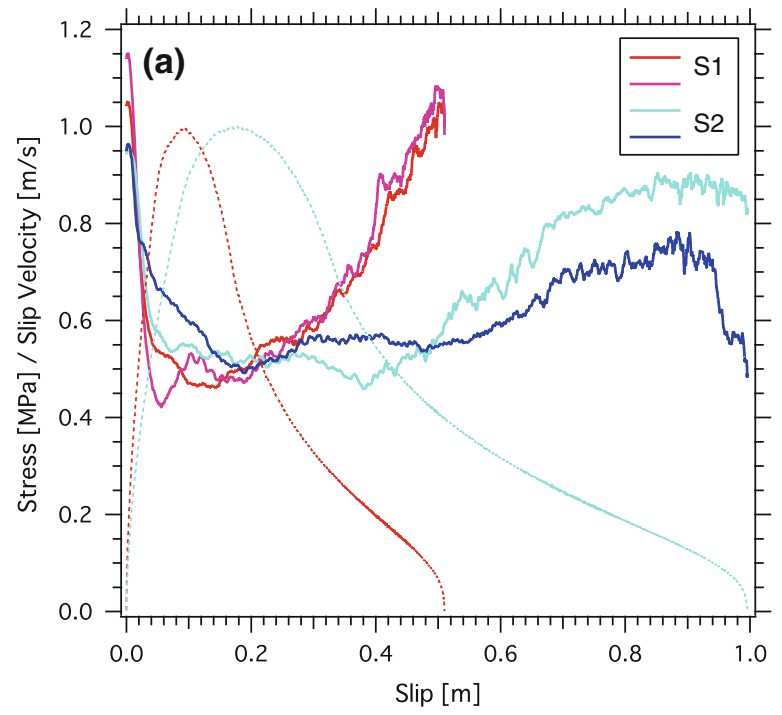

Fig. 4 Results of the experiments for the input of regularized Yoffe functions. a Slip weakening curves for S1 (run number 031, red, and 032, pink) and S2 (041, sky blue, and 048, blue) inputs are shown. b Slip weakening curves for L1 (030, red, and

a large hole was sometimes observed, indicating that a large grain was ripped off the surface and crashed into gouges.

We obtained the slip weakening curves as shown in Fig. 4, where two experimental results are shown for each experiment condition to show the repeatability. In Figs. $4 \mathrm{a}$ and $\mathrm{b}$, the results of experiments $\mathrm{S} 1$ and $\mathrm{S} 2$ and experiments L1 and L2 are shown, respectively. In all cases, steady-stead friction is achieved just before the slip velocity becomes maximum. This feature is consistent with the prediction by Mikumo et al. (2003) and Fukuyama et al. (2003). Some differences between the two experiments under the same condition are observed in S2, which might be caused by a slight difference in the surface conditions during the experiments. But one can see that $\mathrm{S} 2$ behavior is significantly different from L2, showing that the comparison between two models can be considered as significant.

From these experiments, we observed that the initial acceleration of slip affects the weakening process, although its relation does not seem so simple. There is a threshold that changes the weakening mode. As shown in Fig. 4a, when initial acceleration (gradient of slip velocity function at the beginning) is large ( $\mathrm{S} 1$ and S2), friction decreases rapidly and the initial gradient of slip velocity seems to control the frictional strength level ( $\sigma_{\mathrm{f}}$ in Fig. 1) keeping the slip weakening distance

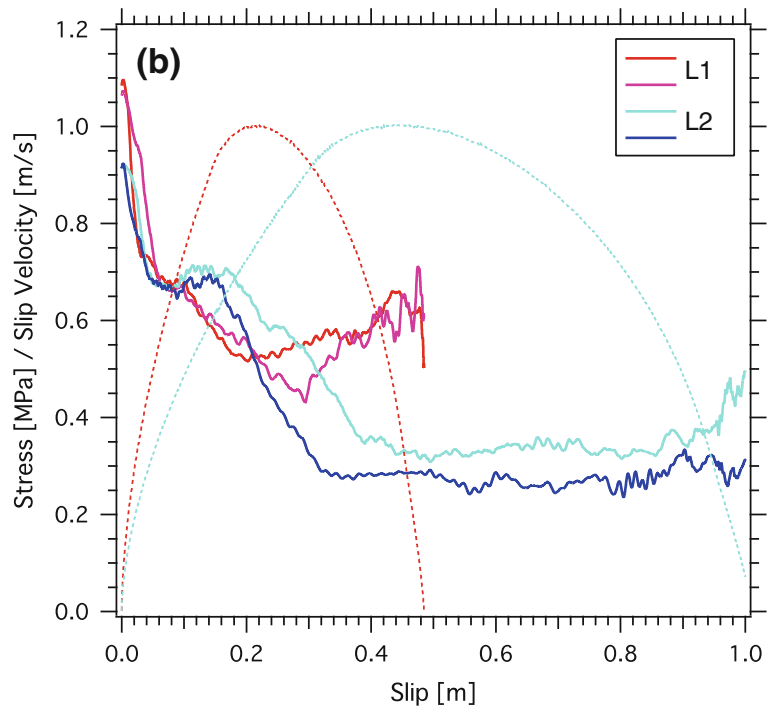

038, pink) and L2 (040, sky blue, and 043, blue) inputs are shown. For both cases, slip velocity functions of S1, S2, L1 and L2 are plotted as a function of slip

constant. In contrast, when initial acceleration is small (L1 and L2), friction decreases gradually and the initial gradient of slip velocity controls the slip weakening distance keeping the slip weakening gradient constant.

These different slip weakening behaviors could be explained by different heat production rate during high slip velocity sliding. Heating the sliding surfaces accelerates the generation of gouge particles caused mainly by the thermal fractures, which then accelerates the weakening of friction.

In addition, it should be noted that a healing occurred at the end of the slip history if a low slip rate portion follows the major part of slip like S1 and S2 as shown in Fig. 4a. This suggests that when the sliding slowed down and thus the temperature on the surface lowered the strength recovered. We do not fully understand this mechanism yet, but this feature should be taken into account as a characteristic feature of the friction behavior at high speed sliding.

\section{Experiments with Denali PS10 slip velocity function}

To understand the slip weakening behavior under more realistic conditions, we used the PS10 seismogram observed during the 2002 Denali, Alaska, earthquake 
Table 2 Conditions of the experiments for the Denali PS10 slip velocity

In Case E1, there are two possible readings for slip-weakening distance

\begin{tabular}{lllll}
\hline $\begin{array}{l}\text { Experiment } \\
\text { Code }\end{array}$ & $\begin{array}{l}\text { Peak slip } \\
\text { velocity }(\mathrm{m} / \mathrm{s})\end{array}$ & Total slip $(\mathrm{m})$ & $\begin{array}{l}\text { Slip-weakening } \\
\text { distance }(\mathrm{m})\end{array}$ & $\begin{array}{l}\text { Normalized } \\
\text { fracture energy }\end{array}$ \\
\hline Case A1 & 0.65 & 1.35 & 0.33 & 0.078 \\
Case A2 & 0.65 & 1.35 & 0.32 & 0.065 \\
Case B1 & 0.325 & 0.65 & 0.20 & 0.036 \\
Case B2 & 0.325 & 0.65 & 0.21 & 0.052 \\
Case C1 & 1.3 & 1.35 & 0.74 & 0.173 \\
Case D1 & 1.3 & 0.65 & 0.38 & 0.077 \\
Case E1 & 0.65 & 2.70 & 0.23 & 0.061 \\
Case E1 & 0.65 & 2.70 & 2.53 & 0.489 \\
Case E2 & 0.65 & 2.70 & 1.64 & 0.456 \\
Case F1 & 0.325 & 2.70 & 2.01 & 0.434 \\
Case G1 & 1.3 & 2.70 & 0.95 & 0.173 \\
Case H2 & 0.325 & 0.32 & 0.19 & 0.023 \\
Case J2 & 0.65 & 0.68 & 0.18 & 0.017 \\
Case K2 & 1.3 & 5.6 & 4.00 & 1.055 \\
Case M2 & 1.3 & 11.2 & 4.30 & 0.877 \\
\hline
\end{tabular}

(Ellsworth et al. 2004) as an input slip velocity function. The PS10 station is located $3 \mathrm{~km}$ off the fault, but located close to the first asperity (or a high slip patch on the fault) (Dreger et al. 2004; Oglesby et al. 2004; Dunham and Archuleta 2004). Since the Denali earthquake occurred on a vertical strike-slip fault, a fault parallel motion on the surface close to the fault can be considered as half of actual fault slip motion, if we consider the mirror image source with respect to the free surface in elastodynamic modeling of fault rupture (e.g., Tse and Rice 1986). We therefore conducted laboratory experiments using the Denali PS10 faultparallel ground velocity motion obtained by Ellsworth et al. (2004) as an input slip velocity function.

The experiments are conducted under a normal stress of $0.5 \mathrm{MPa}$, which is small compared to the in situ condition. This is because we wanted to maintain the non-melting condition as stated before. By changing duration time and amplitude of the input slip velocity function, we created various virtual earthquakes with different stress drop and total slips.

At seismogenic depth, although normal stress applied to the fault might be much higher, the effective normal stress, which is the difference between normal stress and pore pressure, affects the friction behavior and we could not directly measure yet the effective normal stress at such depths. From the analogy of the experiments, if the effective normal stress is of the order of $100 \mathrm{MPa}$, rocks should melt immediately after the slip starts. However, the pseudotachylyte, a foot print of friction melt by high speed slipping, was not frequently observed in the field, suggesting that such high normal stress situation under rock-rock contact is not common at seismogenic depth (Sibson and Toy 2006). Actually, Mizoguchi et al. (2009) reported that if the gouge layer is thick, the temperature does not rise drastically during high speed sliding. Therefore, we do not think the present experimental condition is so different from the real situation at depth.

All the slip velocity functions we employed are described in Table 2. In these experiments, we used two pairs of rock samples. The experiment code that ends ' 1 ' and ' 2 ' indicates these two different rock samples. For the maximum slip velocity, we set 3 conditions (1.3, 0.65 and $0.325 \mathrm{~m} / \mathrm{s}$ ). Since the observed maximum slip velocity (twice of the maximum fault parallel ground velocity) was $3.2 \mathrm{~m} / \mathrm{s}$, the largest slip velocity we used here corresponds to about 0.4 times of the actual peak slip velocity. This rather low slip velocity is also to keep the non-melting condition.

We measures the mechanical error of the apparatus by comparing the input signal with the output rotation speed obtained by the tachometer. The difference was less than $2 \%$ for high slip velocity part and less than 

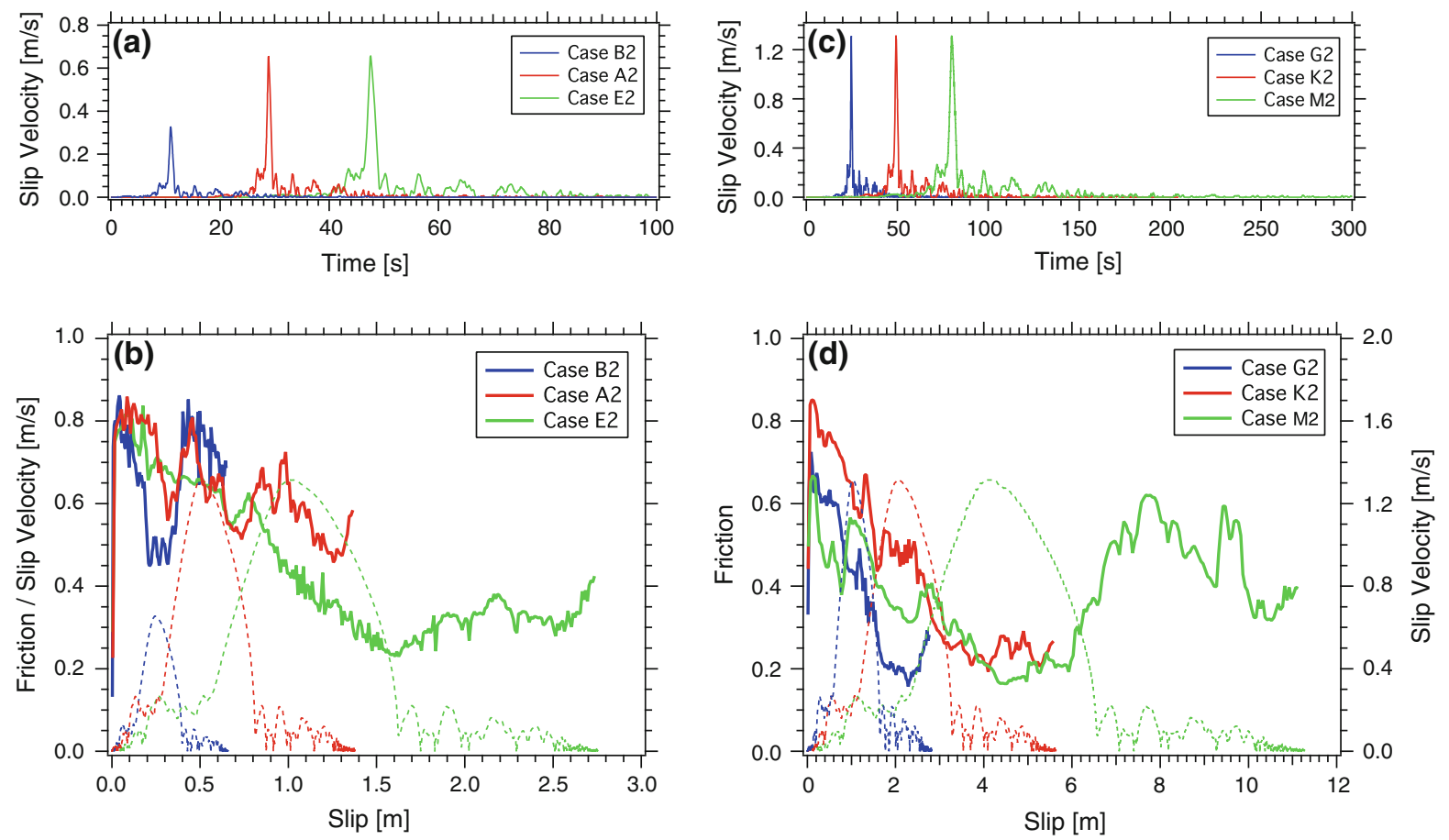

Fig. 5 Results of the experiments for the input of the PS10 velocity ground motion. a Input slip velocity functions for Cases B2, A2, and E2. b Friction coefficient changes of Cases B2, A2 and $\mathrm{E} 2$ as a function of slip (slip weakening curves; solid lines).

$1 \times 10^{-3} \mathrm{~m} / \mathrm{s}$ for the rest, which indicates the apparatus reproduces the input slip velocity quite accurately.

Since the slip velocity function was rather complicated, it was difficult to obtain a slip weakening curve consistent among several runs with the same condition; a small difference in the surface condition made a certain difference in the friction behavior because the surfaces are ground and updated at every moment. Thus, we conducted several experiments on the same condition, excluded the data which were quite different from the other behaviors, and finally averaged the slip weakening curves to obtain the slip weakening curve for the conditions. We think the outliers were caused by the heterogeneous composition of the samples along the rotation axis. This averaging operation corresponds to getting a macroscopic slip weakening curve on a real faulting, which might be observed as an average of microscopic slip weakening curves.

From the experiments, we obtained the shear traction change as a function of slip for several different
Slip velocities as a function of slip are plotted (dotted lines). c Input slip velocity functions for Cases G2, K2 and M2. d Friction coefficient change of Cases G2, K2 and M2 (solid lines). Slip velocities as a function of slip are plotted (dotted lines)

slip rate functions (Fig. 5). Basically all the slip weakening curves are consistent with each other following the same weakening curve. For the cases where the total slip is short (e.g., Case B2 in Fig. 5), strength started to increase during the deceleration stage. In contrast, for the large slip cases (e.g., Cases E2, G2, and K2 in Fig. 5), the healing tends to occur slowly. This feature is consistent with the results obtained by the regularized Yoffe function case described in the previous section. This again suggests that temperature due to heating by frictional slip delays the healing that occurs after the slip weakening process.

From these slip weakening curves, we measured the slip weakening distance $\left(D_{\mathrm{c}}\right)$ by visible inspection where the traction curve changes the sign of its gradient. Automatic detection of slip weakening distance did not work because of the complicated healing process that follows after the weakening process. Once $D_{\mathrm{c}}$ is measured, seismological fracture energy $\left(E_{\mathrm{F}}\right)$ can be measured using Eq. 1 . The measured $D_{\mathrm{c}}$ and corresponding $E_{\mathrm{F}}$ are listed in Table 2. 


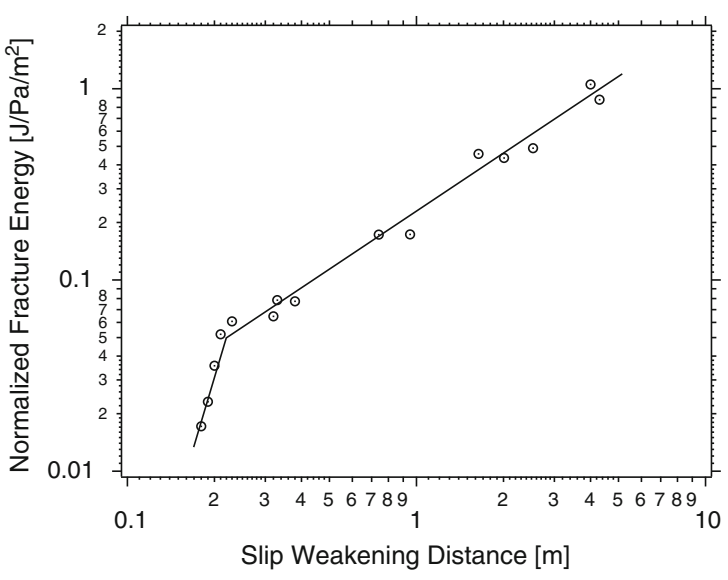

Fig. 6 Logarithmic plots of normalized seismological fracture energy as a function of slip weakening distance. Each open circles corresponds each experiment data. Solid straight line indicates the fitting by two segmented lines

Figure 6 shows the relation between $E_{\mathrm{F}}$ and $D_{\mathrm{c}}$. One can see that there is a kink at around $D_{\mathrm{c}}=0.2 \mathrm{~m}$. It should be emphasized that this kink is not affected by ambiguity of the reading of slip weakening distance; because at small $D_{\mathrm{c}}$, the healing occurred immediately after the $D_{\mathrm{c}}$, these small $D_{\mathrm{c}}$ values and their corresponding fracture energy values are well constrained by the experiment data.

In addition, it should be noted that $D_{\mathrm{c}}$ is estimated at between 2 and $4 \mathrm{~m}$ for the experiments with large displacement and even for the experiment whose total slip exceeds $12 \mathrm{~m}$. This indicates that fault healing starts earlier than the fault motion stops, suggesting that there seems to exist a limit in $D_{\mathrm{c}}$.

\section{Discussions}

We discuss the reason why there is a kink in the relation between $E_{\mathrm{F}}$ and $D_{\mathrm{c}}$. As shown in the results for the regularized Yoffe function (Fig. 4), if the initial slip acceleration is gentle, the friction decreases gently keeping the same slip weakening gradient. But if it is steep, the friction drops abruptly having a similar slip weakening distance. Since we used the slip velocity function of the same shape but different time step and amplitude, as the time step becomes short, the initial acceleration becomes large, which results in a sudden stress drop with a similar $D_{\text {c }}$. We think this is the reason why there is a kink in the relation between
$E_{\mathrm{F}}$ and $D_{\mathrm{c}}$. To investigate the physical aspect of this phenomenon in more detail will be an interesting future work.

In reality, if there is no difference in initial accelerations between small and large earthquakes, there will not be such a kink in the $E_{\mathrm{F}}-D_{\mathrm{c}}$ relation. By looking at the initial part of the $\mathrm{P}$ velocity waveforms of various sizes of earthquakes, the gradient tends to be steep for small earthquake (e.g., Iio 1992; Ellsworth and Beroza 1995; Beroza and Ellsworth 1996), suggesting that the kink in $E_{\mathrm{F}}-D_{\mathrm{c}}$ relation might also exist in nature. However, it should be reminded that the onset of $P$ waveforms includes the effect of spatial extent of the slip zone. If the initial rupture velocity is slow enough, we will be able to conclude that the acceleration of initial $P$ onset corresponds to the slip function at the initiation zone.

Concerning the limit in $D_{\mathrm{c}}$, there appears an increase in strength (healing) after the peak slip velocity is achieved. This healing mechanism seems to be related to the healing observed in the regularized Yoffe experiments for S1 and S2 functions. But it should be noted that for the case of M2, the healing occurs even when the slip velocity is high enough to weaken the fault. Therefore it seems that a slip history dependent feature exists in this process. One possibility is the effect of heat production. Under the non-melting condition, the major weakening process is considered to be the wearing (abrasion) of host rock on the sliding surfaces. And abrasion might be accelerated by the thermal cracking caused by frictional heating. Therefore, frictional heating might be indirectly related to the weakening of the fault. Once the thickness of the gouge zone reaches a critical value where the production of gouges is not required any more because the sliding occurs stably inside the gouge layer. Then, as slip advances, the slipping surface becomes unstable, which increases the friction. But this is a speculation and we did not confirm this mechanism yet. We need to confirm this scenario in some ways.

Finally, it should be noted that for the Denali earthquake, Fukuyama and Mikumo (2007) estimated the slip weakening distance of about $4 \mathrm{~m}$ from the PS10 seismogram. Although their estimated value is considered to be very rough and might include $50 \%$ estimation error, it is worth comparing it with the present experimental result because there are very few estimations reported on the slip weakening distance estimated from seismological observations. 


\section{Conclusions}

We conducted a series of laboratory experiments to investigate the relation of slip weakening distance and seismological fracture energy. We first used a regularized Yoffe function and observed that depending on the initial acceleration, there are two modes of weakening, a rapid weakening with constant slip weakening distance and a gentle weakening with constant slip weakening gradient. We also found that if there is rather long slip duration after the peak slip velocity, healing starts to occur during slipping. We used the Denali PS10 seismogram as a proxy for real fault motion. The results suggest that the slip weakening does not seem to be scale independent but there is a critical value where the scaling of slip weakening changes. In addition, there seems to exist a maximum slip weakening distance (or maximum seismological fracture energy). In the Inada granite with PS10 seismogram, the cut-off was $0.2 \mathrm{~m}$ and maximum slip weakening distance was $\sim 4 \mathrm{~m}$. The $4 \mathrm{~m}$ slip weakening distance is consistent with the estimate by Fukuyama and Mikumo (2007).

Acknowledgments Comments by two anonymous reviewers are very helpful to improve the manuscript.

Open Access This article is distributed under the terms of the Creative Commons Attribution Noncommercial License which permits any noncommercial use, distribution, and reproduction in any medium, provided the original author(s) and source are credited.

\section{References}

Andrews DJ (2002) A fault constitutive relation accounting for thermal pressurization of pore fluid. J Geophys Res 107:2363. doi:10.1029/2002JB001942

Beresnev IA (2003) Uncertainties in finite-fault slip inversions: to what extent to believe? (A critical review). Bull Seismol Soc Am 93:2445-2458

Beroza GC, Ellsworth WL (1996) Properties of the seismic nucleation phase. Tectonophys 261:209-227

Bizzarri A, Cocco M (2006) A thermal pressurization model for the spontaneous dynamic rupture propagation on a three-dimensional fault : 1 methodological approach. J Geophys Res 111:B05303. doi:10.1029/2005JB003862

Broberg KB (1999) Cracks and fracture. Academic Press, San Diego, CA, 752 pp

Chambon G, Schmittbuhl J, Corfdir A (2002) Laboratory gouge friction: seismic-like slip weakening and secondary rateand state-effects. Geophys Res Lett 29(10):1366. doi:10. 1029/2001GL014467
Chester FM, Chester JS (1998) Ultracataclasite structure and friction processes of the punchbowl fault San Andreas system California. Tectonophys 295:199-221

Dieterich JH (1978) Modeling of rock friction 1. Experimental results and constitutive equations. J Geophys Res 84: 2161-2168

Di Toro G, Goldsby DL, Tullis TE (2004) Friction falls towards zero in quartz rock as slip velocity approaches seismic rates. Nature 427:436-439

Di Toro G, Nielsen S, Pennacchioni G (2005) Earthquake rupture dynamics frozen in exhumed ancient faults. Nature 436: 1009-1012. doi:10.1038/nature03910

Dreger D, Kaverina A (2000) Seismic remote sensing for the earthquake source process and near-source strong shaking: A case study of the October 161999 hector mine earthquake. Geophys Res Lett 27:1941-1944

Dreger DS, Oglesby DD, Harris R, Ratchkovski N, Hansen R (2004) Kinematic and dynamic rupture models of the November 32002 Mw7.9 Denali, Alaska, earthquake. Geophys Res Lett 31:L04605. doi:10.1029/2003GL018333

Dunham EM, Archuleta RJ (2004) Evidence for a supershear transient during the 2002 Denali Fault earthquake. Bull Seismol Soc Am 94(6B):S256-S268

Ellsworth WL, Beroza GC (1995) Seismic evidence for an earthquake nucleation phase. Science 268:851-855

Ellsworth WL, Celebi M, Evans JR, Jensen EG, Kayen R, Metz MC, Nyman DJ, Roddick JW, Spudich P, Stephens CD (2004) Near-field ground motion of the 2002 Denali fault, Alaska, earthquake recorded at Pump Station 10. Earthq Spect 20:597-615

Fukuyama E, Mikumo T (1993) Dynamic rupture analysis: inversion for the source process of the 1990 Izu-Oshima, Japan, earthquake (M-6.5). J Geophys Res 98:6529-6542

Fukuyama E, Mikumo T (2007) Slip-weakening distance estimated at near-fault stations. Geophys Res Lett 34:L09302. doi:10.1029/2006GL029203

Fukuyama E, Mikumo T, Olsen KB (2003) Estimation of the critical slip-weakening distance: theoretical background. Bull Seismol Soc Am 93:1835-1840

Goldsby DL, Tullis TE (2002) Low frictional strength of quartz rocks at subseismic slip rates. Geophys Res Lett 29:1844. doi:10.1029/2002GL01240

Guatteri, Spudich P (2000) What can strong-motion data tell us about slip-weakening fault-friction laws?. Bull Seismol Soc Am 90:98-116

Hartzell SH, Heaton TH (1983) Inversion of strong ground motion and teleseismic waveform data for the fault rupture history of the 1979 Imperial Valley, California, earthquake. Bull Seismol Soc Am 73:1553-1583

Hirose T, Shimamoto T (2003) Fractal dimension of molten surfaces as a possible parameter to infer the slip-weakening distance of faults from natural pseudotachylites. J Struct Geol 25:1569-1574

Hirose T, Shimamoto T (2005) Growth of molten zone as a mechanism of slip weakening of simulated faults in gabbro during frictional melting. J Geophys Res 110:B05202. doi:10.1029/2004JB003207

Ida Y (1972) Cohesive force across the tip of a longitudinal-shear crack and Grifflth's specific surface energy. J Geophys Res 77:3796-3805 
Ide S (2002) Estimation of radiated energy of finite-source earthquake models. Bull Seismol Soc Am 92:2994-3005

Ide S, Takeo M (1997) Determination of constitutive relations of fault slip based on seismic wave analysis. J Geophys Res 102:27379-27391

Iio Y (1992) Slow initial phase of the P-wave velocity pulse generated by microearthquakes. Geophys Res Lett 19: 477-480

Ji C, Wald DJ, Helmberger DL (2002) Source description of the 1999 Hector Mine, California, earthquake, part II: complexity of slip history. Bull Seismol Soc Am 92:1208-1226

Kostrov BV, Das S (1988) Principles of earthquake source mechanics. Cambridge University Press, Cambridge, $286 \mathrm{pp}$

Lachenbruch AH (1980) Frictional heating, fluid pressure, and the resistance to fault motion. J Geophys Res 85:6249-6272

Mase CW, Smith L (1987) Effects of frictional heating on the thermal, hydrologic, and mechanical response of a fault. J Geophys Res 92:6249-6272

Matsu'ura M, Kataoka H, Shibazaki B (1992) Slip-dependent friction law and nucleation processes in earthquake rupture. Tectonophys 211:135-148

Melosh HJ (1996) Dynamical weakening of faults by acoustic fluidization. Nature 379:601-606

Mikumo T, Olsen KB, Fukuyama E, Yagi Y (2003) Stressbreakdown time and slip-weakening distance inferred from slip-velocity functions on earthquake faults. Bull Seismol Soc Am 93:264-282

Mikumo T, Fukuyama E (2006) Near-source released energy in relation to fracture energy on earthquake faults. Bull Seismol Soc Am 96: 1177-1181. doi:10.1785/0120050121

Mizoguchi K, Fukuyama E (2008) Friction of granite and gabbro at subseismic sliprate. EOS Trans AGU 89(53) (Fall Meet. Suppl., T13A-1903)

Mizoguchi K, Fukuyama E (2009) Frictional behavior of simulated faults at subseismic slip rate (in preparation)

Mizoguchi K, Hirose T, Shimamoto T, Fukuyama E (2007) Reconstruction of seismic faulting by high-velocity friction experiments: an example of the 1995 Kobe earthquake. Geophys Res Lett 34:L01308. doi:10.1029/2006GL027931

Mizoguchi K, Hirose T, Shimamoto T, Fukuyama E (2009) High-velocity frictional behavior and microstructure of fault gouge obtained from Nojima fault southwest Japan. Tectonophys 471:285-296

Oglesby DD, Dreger DS, Harris RA, Ratchkovski N, Hansen R (2004) Inverse kinematic and forward dynamic models of the 2002 Denali fault earthquake Alaska. Bull Seismol Soc Am 94:S214-S233

Ohnaka M, Kuwaharam Y, Yamamoto K (1987) Constitutive relations between dynamic physical parameters near a tip of the propagating slip zone during stick-slip shear failure. Tectonophys 144:109-125

Palmer AC, Rice JR (1973) The growth of slip surfaces in the progressive failure of over-consolidated clay. Proc Roy Soc Lond A 332:527-548

Piatanesi A, Tinti E, Cocco M, Fukuyama E (2004) The dependence of traction evolution on the earthquake source time function adopted in kinematic rupture models. Geophys Res Lett 31:L04609. doi:10.1029/2003GL019225
Rice JR (2006) Heating and weakening of faults during earthquake slip. J Geophys Res 111:B05311. doi:10.1029/ 2005JB004006

Sekiguchi H, Iwata T (2002) Rupture process of the 1999 Kocaeli, Turkey, earthquake estimated from strong-motion waveforms. Bull Seismol Soc Am 92:300-311

Sibson RH (1973) Interactions between temperature and pore fluid pressure during earthquake faulting — a mechanism for partial or total stress relief. Nature 243:66-68

Sibson RH, Toy VG (2006) The habitat of fault-generated pseudotachylyte: presence vs absence of friction-melt. In: Abercrombie R, McGarr A, Di Toro G, Kanamori H (eds) Earthquakes: radiated energy and the physics of faulting, geophysical monograph series 170. American Geophysical Union, pp 153-166

Shimamoto T, Tsutsumi A (1994) A new rotary-shear high-speed frictional testing machine: its basic design and scope of research. Struct Geol (J Tectonic Res Group Japan) 39: 65-78 (in Japanese with English abstract)

Shimamoto T, Hirose T, Mizoguchi K, Noda H (2003) Highvelocity friction of faults and earthquake generating process: current status and future perspectives. J Geography 112:979-999 (in Japanese with English abstract)

Spray JG (2005) Evidence for melt lubrication during large earthquakes. Geophys Res Lett 32:L07301. doi:10.1029/ 2004GL022293

Tinti E, Fukuyama E, Piatanesi A, Cocco M (2005) A kinematic source-time function compatible with earthquake dynamics. Bull Seismol Soc Am 95:1211-1223. doi:10.1785/ 0120040177

Tinti E, Spudich P, Cocco M (2005) Earthquake fracture energy inferred from kinematic rupture models on extended faults. J Geophys Res 110:B12303. doi:10.1029/2005JB003644

Tinti E, Cocco M, Fukuyama E, Piatanesi A (2009) Crustal earthquake instability in relation to the depth variation of frictional slip properties. Geophys J Int 177:1205-1220

Tse ST, Rice JR (1986) Crustal earthquake instability in relation to the depth variation of frictional slip properties. J Geophys Res 91:9452-9472

Tsutsumi A, Shimamoto T (1997) High-velocity frictional properties of gabbro. Geophys Res Lett 24:699-702

Wald DJ, Heaton TH (1994) Spatial and temporal distribution of slip for the 1992 Landers, California, earthquake. Bull Seismol Soc Am 84:668-691

Wibberley CAJ, Shimamoto T (2005) Earthquake slip weakening and asperities explained by thermal pressurization. Nature 436: 689-692. doi:10.1038/nature03901

Yamashita T (2000) Generation of microcracks by dynamic shear rupture and its effects on rupture growth and elastic wave radiation. Geophys J Int 143:395-406

Yoshida S, Koketsu K, Shibazaki B, Sagiya T, Kato T, Yoshida Y (1996) Joint inversion of the near- and far-field waveforms and geodetic data for the rupture process of the 1995 Kobe earthquake. J Phys Earth 44:437-454 